\title{
Construction of Hybrid English Courses Based on Mobile Software Assisted Teaching in Chinese Universities
}

\author{
W. N. Dou \\ Department of Foreign languages, School of Human and \\ Law, Beijing University of Civil Engineering and \\ Architecture \\ 1 Zhanlanguan Rd., Xicheng District Beijing 100044, \\ China \\ 0086-18801009124 \\ douwenna@bucea.edu.cn
}

\author{
$X$. Y. Song \\ School of Environment and Energy Engineering, Beijing \\ University of Civil Engineering and Architecture \\ 1 Zhanlanguan Rd., Xicheng District Beijing 100044, \\ China \\ 0086-1346664191 \\ 1585014510@qq.com
}

\begin{abstract}
Developing "Internet + Education" and promoting the sharing of high-quality educational resources are the major trends of national educational reformation and development in China. As a compulsory course for undergraduates, it is necessary to reform the traditional mode of English teaching in order to better meet the needs of cultivating internationalized and practical talents in the Internet era. Therefore, based on the project of "Seminar Course" in one Chinese university, this paper explores the construction of Hybrid English Courses by employing Superstar Platform which is a mobile learning software. It aims to establish a new teaching mode which could improve undergraduates' language use ability in higher education in China.
\end{abstract}

\section{CCS Concepts}

- Applied computing $\rightarrow$ Education $\rightarrow$ Computer-managed instruction

\section{Keywords}

Higher Education Reformation; Mobile Software Assisted Teaching; Hybrid English Courses; Teaching Model Reformation.

\section{INTRODUCTION}

The hybrid teaching mode integrates online learning platform (online) with the traditional classroom teaching (offline). In this way, teachers put videos and other relevant learning materials online, which enable students to learn relevant theoretical knowledge in advance. This new teaching mode gets rid of the repeated teaching contents in traditional teaching mode [1-4]. In class, teachers organize students to learn knowledge in the form of discussion. During the whole process, teachers takes the role of answering questions, solving doubts, leading and monitoring, which truly realizes the innovation of "learner-centered".

The "Seminar Course" project refers to the reformation of the

Permission to make digital or hard copies of all or part of this work for personal or classroom use is granted without fee provided that copies are not made or distributed for profit or commercial advantage and that copies bear this notice and the full citation on the first page. Copyrights for components of this work owned by others than ACM must be honored. Abstracting with credit is permitted. To copy otherwise, or republish, to post on servers or to redistribute to lists, requires prior specific permission and/or a fee. Request permissions from Permissions@acm.org.

ICIET 2020, March 28-30, 2020, Okayama, Japan

(C) 2020 Association for Computing Machinery.

ACM ISBN 978-1-4503-7705-8/20/03 ..\$15.00

DOI: https://doi.org/10.1145/3395245.3396435 classroom teaching based on the hybrid teaching mode, which integrates large class teaching with small class discussion. It not only arouses the initiative of teachers and students but also plays an important role in improving the quality of teaching and learning. Based on that, Beijing University of Civil Engineering Architecture (BUCEA) in China officially launched the pilot work of "Seminar Course" in the fall semester of 2017.

The "Seminar Course" is a new practice of improving the quality of talent cultivation proposed by BUCEA on the basis of further deepening the reformation of undergraduate education. On one hand, this teaching mode focuses on deep learning experience and open exploration. It aims to further stimulate students' learning interest, intellectual motivation and exploration spirit. On the other hand, it pushes teachers to cultivate and improve students' abilities of independent learning, critical analysis, innovative thinking, communication, and teamwork. Thus, this new teaching mode comprehensively improves students' academic literacy and comprehensive ability as a whole.

Based on the background of Higher Education Reformation in the Internet era and the requirements for the cultivating applicationoriented talents in Chinese universities, the author opened an English course called "Cross-Cultural Academic English Reading" in 2018, which belongs to compulsory courses for undergraduates of non-English major. Relying on "Seminar Course" project and "Superstar Platform" which is a mobile learning software, the construction of hybrid English course was being carried out.

\section{OBJECTIVES OF COURSE CONSTRUCTION}

\subsection{Reinforcing Basic Language Skills}

For higher education, English is a tool for people to communicate with each other and acquire knowledge. Therefore, one of the main objectives of this course is to consolidate students' basic language skills. In this course, language knowledge can be divided into two parts, including output knowledge and input knowledge. Acquiring input knowledge is the basis of acquiring output knowledge. English reading and listening belong to the former. In the process of language learning, enhancing students' English reading ability plays a fundamental role in improving students' comprehensive ability of language use.

Therefore, this course will dig deep into reading materials from the easy to the difficult in order to help students improve their reading comprehension skills step by step. The reading materials chosen for this course are shown in Table 1 below. 
Table 1. Three levels of reading materials

\begin{tabular}{cll}
\hline \hline No. & Reading Materials & Degree of Difficulty \\
\hline 1 & General English Discourses & Low \\
2 & Exam-oriented English Discourses & Medium \\
3 & Academic Literature & High \\
\hline \hline
\end{tabular}

\subsection{Enhancing Cross-cultural Communication Capacity}

In July 2010, Ministry of Education has released "The Outline of the National Plan for Medium-and Long-term Education Reform and Development (2010-2020)" which put forward higher requirements for higher education in terms of undergraduates' cultivation in China. The documents demonstrate that it is necessary for educators to cultivate a large number of international students with international vision, understanding of international rules, and being able to participate in international affairs and international competition. From the above statement, it shows that cultivating undergraduates' cross-cultural communication ability is one of the effective ways for higher education to achieve internationalization under the strategic tentative idea of "One Belt and One Road" proposed by President Xi Jinping in 2013 [5].

Accordingly, this course takes the English discourses as the carrier of culture, intends to help students understand the language content and makes an in-depth analysis of differences between Chinese and western cultures in the process of learning. Through this course, students can apply cross-cultural theoretical knowledge to the practice, so as to become a talent with all-round development.

\subsection{Training Critical Thinking Ability}

With the increasing popularity of the Internet, a large amount of information squeezes into people's life and study, undergraduates are facing not only the acquisition of knowledge, but also the choice of knowledge. Therefore, cultivating students' critical thinking is the need of cultivating innovative spirit of them. [6].

Thus, based on the perspective of discourse analysis, this course allows students to have free collision of thoughts in the discussion between teachers and students or among students themselves. Taking group discussion as the entry point and English academic reading as the learning carrier, students not only pay attention to the language form, but also lay more emphasis on the meaning of language in the process of reading, so as to use language properly.

\subsection{Promoting Chinese Traditional Culture}

The teaching targets in this course are mainly those who are going to the United States for further study after two years of undergraduate study in China. On the premise of consolidating basic language skills, more attention should be paid to the ideological education of students, especially the cultivation of correct values. They are not only the "brand" of BUCEA, but also the "image representative" of Chinese university students. Therefore, this course organically combines language knowledge, ability improvement, patriotism and other values to cultivate promising young people with the craftsman spirit of BUCEA.

Based on that, this course provides a platform for students to understand the different language cultures with the method of comparative analysis. Apart from that, this course pays more attention to the diffusion of Chinese culture, especially Chinese excellent traditional culture and values. Through learning this course, students have the ability to promote the development of Chinese excellent traditional culture. Conversely, students' national self-confidence will be strengthened accordingly, which can play an important role in facilitating the process of studying in new environment with different culture.

\section{CONTENTS OF COURSE CONSTRUCTION}

\subsection{In-Depth Analysis of English Discourses of Different Genres}

At the level of language learning, this course enables students to improve their ability of analyzing and understanding English reading discourses by using various approaches. The discourse genres chosen by this course can be divided into three categories: general discourses, exam-oriented discourses and academic articles.

Firstly, general discourses chiefly include news, current affairs, government reports, speeches and other materials. Secondly, the exam-oriented discourses make a special explanation of the reading materials in the TOEFL IBT, which depends on the fact that students in this class need to pass the TOEFL IBT in the first two years of university in BUCEA, which are the prerequisites for going to Auburn University in USA. Thirdly, given that academic articles should focus on students' professional background, the selected papers need to be related to students' major. Thus, in this course, academic journals about "Environmental Engineering" are preferred, which intends to improve students' academic reading ability and improve their comprehensive language use ability simultaneously. See Table 2 for details.

Table 2. English Discourses Of Different Genres

\begin{tabular}{lll}
\hline \hline No. & Different Genres & Reading Materials \\
\hline 1 & $\begin{array}{l}\text { General English } \\
\text { Discourses }\end{array}$ & $\begin{array}{l}\text { News, current affairs, government } \\
\text { reports, speeches, etc. }\end{array}$ \\
\hline 2 & $\begin{array}{l}\text { Exam-oriented } \\
\text { English Discourses }\end{array}$ & Reading section in the TOEFL IBT \\
\hline 3 & $\begin{array}{l}\text { Academic } \\
\text { Literature }\end{array}$ & $\begin{array}{l}\text { Academic journals about } \\
\text { "Environmental Engineering" }\end{array}$ \\
\hline \hline
\end{tabular}

\subsection{Applying Genre Analysis to Analyze the Structure and Communicative Purpose of English Discourses}

"Genre Analysis" is mainly used in the field of discourse analysis, which is proposed and developed by English scholar Swales. In his opinion, genre represents typed communicative practice, which usually has a specific communicative purpose and presents a specific communicative paradigm, which is recognized by members of the communicative group and gradually forms a relatively stable discourse structure [7]. Mastering the textual structure of a particular genre is helpful for learners to quickly integrate into a certain discourse system and master the basic structure of the different types of discourse.

Therefore, this course is based on the theory of "Genre Analysis". From the macro level, firstly the structure and function of various discourses are deeply analyzed, so that students can quickly grasp the structure of this type of discourse through the study of limited English discourses, so as to enhance their overall understanding of English discourses. Secondly, students will be organized to 
discuss the communicative purposes of each step structure and to evaluate the logical thinking of the author's discourse, so as to explain their own views. Thirdly, students are required to make a comparative analysis of the cultural differences between Chinese and western authors' literature (all the papers are written in English.), identity differences between authors and readers, and work out the effectiveness of communicative purposes. In this way, students are inspired to think more deeply from the meaning of one discourse to the communicative purpose behind it.

At the micro level, teachers lead the students to analyze the language features that construct each structure of the discourse. First of all, from vocabulary to syntax, teachers lead students to analyze difference discourse this category in marked materials and summarize the methods. The above teaching contents can be shown in Table 3 below.

Table 3. Application of genre analysis

\begin{tabular}{ll}
\hline \hline Levels & Contents of Analysis \\
\hline Macro & Basic structures \\
& Functions \\
& Communicative purposes \\
& Cultural differences \\
\hline Micro & Words \\
& Phrases (discourse markers) \\
& Sentence patterns \\
\hline
\end{tabular}

After class, teachers will invite students to participate in the recording of 10-min video, stimulate students' interest in learning and cultivate students' critical thinking at the same time, which can lay a solid foundation for students to write English papers in the following English learning.

\subsection{Comparison Cultural Differences between Chinese and Western Authors Based on Their Academic Writing}

In 2018, universities in China held the first national cross-cultural English speech contest for undergraduates, which reflected the increasing status of cross-cultural communication competence in English teaching in higher education. Based on the above considerations, the main teaching content consists of two parts in this course:

On one hand, the teaching of theoretical knowledge includes two aspects: cross-cultural theoretical knowledge and theories of discourse linguistics. As for the former, it includes the definition of culture, the definition of communication, the purpose of crosscultural communication, Hofstede's value dimension theory [8], Hall's high-context low-context orientation theory [9] and TingToomey's Face Negotiation Theory [10]. As for the teaching of the theory of discourse linguistics, it contains Genre Analysis, Functional steps, Meta-discourse Theory and Thematic Progressive Model. The purpose is to guide students to understand the knowledge of cross-cultural communication and textual linguistics from the theoretical level, so as to lay a solid theoretical foundation for training students' cross-cultural ability through discourse analysis.

On the other hand, the ability of solving practical problems with theoretical knowledge is emphasized. This course allows students to compare and analyze the language structure features and internal ideology of Chinese and western authors' academic articles and how their different values are expressed through different language forms. In this way, it enables students to have a deeper understanding of the cross-cultural connotation of English discourse. The above statement can be presented in Table 4 .

Table 4. Cross-cultural communication

\begin{tabular}{ll}
\hline \hline Aspects & Detailed information \\
\hline $\begin{array}{l}\text { Theoretical } \\
\text { knowledge }\end{array}$ & $\begin{array}{l}\text { Cross-cultural theoretical knowledge } \\
\text { Theories of discourse linguistics }\end{array}$ \\
\hline $\begin{array}{l}\text { Practical } \\
\text { ability }\end{array}$ & $\begin{array}{l}\text { Compare the language structure features and } \\
\text { acternal ideology of Chinese and western authors' } \\
\end{array}$ \\
& $\begin{array}{l}\text { Analyze how their different values are expressed } \\
\text { through different language forms. }\end{array}$ \\
\hline \hline
\end{tabular}

\subsection{Discussion and Presentation of Chinese Excellent Traditional Culture}

In line with "Ideological Education" as the guidance, this course will select some discussion points connotating traditional culture of China as one main component of teaching contents. In the real teaching practice, students are driven by teacher's question to appreciate the Chinese traditional culture. Specifically speaking, this course includes three types of actives:

Firstly, teachers recorded the traditional Chinese cultural values and theories in the text before class and made them into 10-minute small video. Students are required to learn before class. In class, teachers adopt the mode of "Expanding Thinking" to organize the students to discuss the traditional Chinese values contained in the discourse analysis. After class, students are given more reading materials to analyze.

The second is to carry out the performance of "Comparison Between Chinese and Western Cultures", which covers a variety of cultural genres, including society, interpersonal relationship, history and education. It shows the influence of western culture on people's thoughts and behaviors from different aspects, so as to help readers feel the impact of different cultures personally and deepen their identification with different cultures and their own cultures. Specially, this course leads students to appreciate the cultural diversity of architecture, through the comparison of Chinese and western architectural design concepts, layout and the selection of building materials. Furthermore, students are required to discuss the embodiment of Chinese and western philosophy in architecture, which highlights school-based characteristics. What's more, the course also provides the knowledge of Chinese culture corresponding to the theme. The main purpose of this activity is to deepen students' understanding of Chinese culture while they are learning about western culture, which can lay a solid foundation for students' further development. During the process of studying abroad, students can make their voices heard on the world stage.

Thirdly, this course provides several cross-cultural activities. One is extracurricular activities named "The Journey of Cross-Culture Communication". Students need to apply what they have learnt about the cross-cultural communication knowledge and skills to the practice. They are required to look for the "case" in their daily life, adhering to the procedure of "observation - interview recording - transcription - analysis - writing practice report". At the end, they will present their research report within 5 minutes. 
The purpose is to enable students to perceive the position and influence of Chinese culture on the world stage and to enhance the students' cultural confidence accordingly. It can be demonstrated in Table 5.

Table 5. Chinese Excellent Traditional Culture

\begin{tabular}{|c|c|c|}
\hline No. & Contents & Detailed information \\
\hline \multirow{4}{*}{1} & \multirow[t]{4}{*}{ Video recording } & Learn before class \\
\hline & & Discussion in class \\
\hline & & Write reports after class \\
\hline & & Present next class \\
\hline \multirow{4}{*}{2} & \multirow{4}{*}{$\begin{array}{l}\text { Designated } \\
\text { topic discussion }\end{array}$} & Society \\
\hline & & Interpersonal relationship \\
\hline & & History \\
\hline & & Education \\
\hline \multirow{3}{*}{3} & \multirow{3}{*}{$\begin{array}{l}\text { Extracurricular } \\
\text { activities }\end{array}$} & Look for the "case" in daily life \\
\hline & & $\begin{array}{l}\text { Procedure: "observation - interview - } \\
\text { recording - transcription - analysis - writing } \\
\text { practice report". }\end{array}$ \\
\hline & & $\begin{array}{l}\text { Present their research report within } 5 \\
\text { minutes. }\end{array}$ \\
\hline
\end{tabular}

\section{DESIGN NOTION OF HYBRID ENGLISH COURSES}

In terms of online part, teachers upload the recorded video to the platform and supervises the students' learning progress at any time by relying on the mobile network learning software platform of "Superstar". At meantime, teachers can answer questions and solve doubts via the platform so as to urge the students to complete the online learning tasks by setting the "Task Passing Mode", which can effectively arouse students' interest. As for the student, they can learn knowledge from watching short videos in advance according to the requirements, publish their own opinions in BBS and upload their papers online, which can make the content sharing come true.

In terms of outline part, teachers are in charge of observing the status of the group discussion in class. Teachers use various activity modules in the "Superstar Platform" to guide and stimulate the discussion of students. Through group presentation, teachers can promote their peers to form a healthy learning competition relationship, so as to improve students' learning efficiency. The above statements about course design can be seen in the Figure 1 as below.

According to the design notion, it combines online with offline English teaching into a cyclic process that is from "PracticeReflection" to "Re-Practice and Re-reflection".

For students, it is the process of knowledge learning and practice after class(online). Firstly, they need to learn the theoretical knowledge of cultural specialty. Secondly, they have to summarize the key points and difficulties of knowledge. Thirdly, they are required to apply the theoretical knowledge to practical activities. Finally, they should reflect on and summarize the activities in class so as to consolidate the learning effect of crosscultural related knowledge.

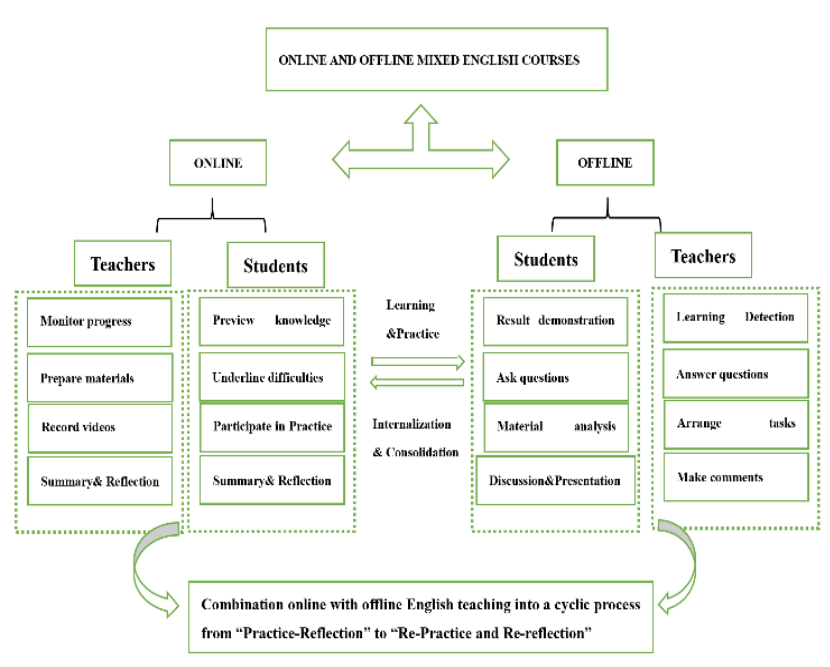

Figure 1. Hybrid English Course Design

In class (offline), it is the process of knowledge internalization and consolidation. Firstly, they need to show the effect of afterclass learning. Secondly, they have to raise questions in the process of learning. Thirdly, they are required to analyze crosscultural materials. Finally, they should have a group discussion.

For teachers, they need to monitor the progress of students' learning after class (online). Secondly, they have to prepare materials of next lesson for students' learning. Thirdly, they need to record the main learning contents in a short video. Finally, they should summarize and reflect on students' practice reports, so as to improve the existing teaching methods.

In class (offline), teachers need to test students' learning effect. Secondly, they have to answer questions and analyze difficult knowledge. Thirdly, they need to assign practical tasks of afterclass learning for students. Finally, they should comment on students' performance. The combination of hybrid teaching constitutes a cyclic process, which leads to a great improvement of English teaching and learning effectiveness.

\section{ESTABLISHMENT OF CROSS- CULTURAL ACADEMIC ENGLISH READING COURSE}

Based on the above principle, Cross-Cultural Academic English Reading Course was established as follows:

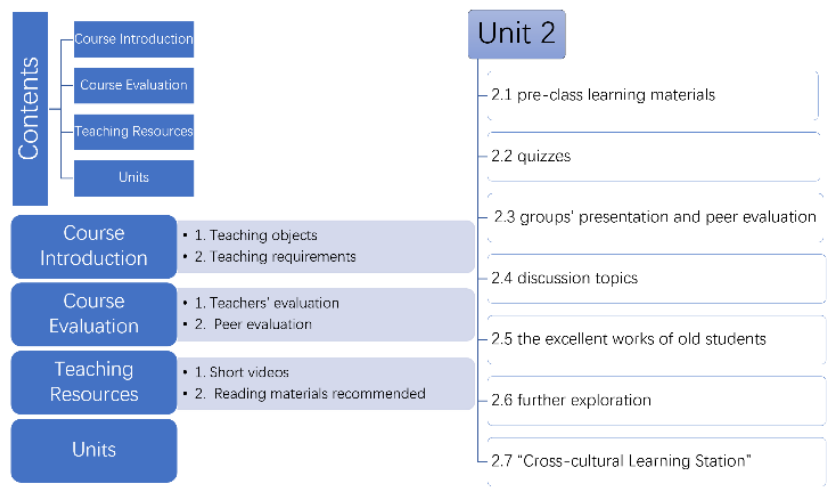

Figure 2. Cross-Cultural Academic English Reading Course 
As shown in the figure above, in the upper left corner, it shows the contents of this course which includes four parts, namely, Course Introduction, Course Evaluation, Teaching Resources and Units. Under the box, the page illustrates the detailed information of the first three parts.

On the right column of this page, it shows the detailed information of each unit. By examining Unit 2, 2.1 refers to pre-class learning materials, including 10-min video learning materials about the one type of discourse genre- Introduction of Newspaper Headlines.

Next, corresponding learning effects are detected in the part of 2.2. Teachers will use serval quizzes based on the main idea of learning materials before class in order to check student's preview effect.

2.3 refers to groups' presentation and peer evaluation. In this part, teachers gave timely feedback to students about their last week's assignments. According to the feedback, students in this class need to present their report. At the same time, other students need to give their comments based on other students' performances.

In 2.4 discussion topics are assigned to students. Students use the theoretical knowledge in the video material before class to analyze the different English discourses of the same genre assigned by teachers to each group. Meanwhile, teachers guide each group to complete the content of discourse analysis step by step through the form of questions. Finally, each group are assigned to finish today's homework.

2.5 plays a role of "Model". After the delivery of the assignment, new students can refer to the excellent works of old students. In this way, it not only provides students with the right guidance, but also reduces the difficulties of the tasks for students in the new semester.

As for the part of 2.6, teachers will upload relatively difficult English reading materials of the same genre to provide more support to further enhance students' reading ability.

2.7 refers to the part of "Cross-cultural Learning Station" which analyzes the cultural knowledge contained in each assigned reading article. In this way, it can expand students' cultural vision and improve their cross-cultural communication ability. By comparing the Chinese and western cultures with the corresponding themes, this course provides more information and ideological guidance for students to deeply understand and carry forward Chinese traditional culture.

\section{MULTI-MEANS OF COURSE EVALUATION}

This course uses a variety of evaluation methods, combining teacher's evaluation with students' evaluation, combining final evaluation with formative evaluation.

\subsection{Evaluation from Teachers}

As long as students participate in each link of course activities, teachers can make scientific statistics through the data provided by "Superstar Platform" in real time. Based on that, it is easy for teachers to timely adjust the teaching progress in order to improve the teaching effect.

For example, based on "Superstar Platform", teachers can randomly selected students to answer questions. If one student was chosen, his/her image and the score would appear on the screen immediately, which not only arouses students' attention but also encourages other students to actively participate in classroom activities. Apart from that, according to the statistics of "Superstar Platform", some students who were not chosen to answer the question at random can be "Selected" on purpose by teachers. In this way, it can improve the fairness of students' engagement and let every student have the opportunity to participate in classroom interaction.

"Testing" function of "Superstar Platform" can improve teaching efficiency. In order to achieve a rapid examination of students' knowledge. "Superstar Platform" can provides real-time statistics of the correct rate of students' performance, so that teachers can quickly know the degree of students' understanding and application of new knowledge. Thus, teachers can quickly adjust the teaching steps. For instance, when learning Unit 4, the statistics showed that almost the whole class can answer the questions correctly, so teachers could move to the next teaching step directly without more explanation, while when learning Unit 3 , one third of the students in the class gave the wrong answer to a question. In this case, teachers had to explain the question in depth to ensure the students to understand the question before continuing to the next teaching task.

As for teachers, it provides a great convenience. In the traditional teaching activities, students feel so embarrassed to put forward their own questions in class that teachers sometimes take it granted that everyone had mastered the new knowledge. By using "Superstar Platform", teachers can detect students' performance from statistics. Thus, it is possible for teachers to provide help to students who may have difficulties individually. This kind of computer-aided instruction course respects students' self-esteem and improves the effectiveness of teaching at the same time.

\subsection{Peer Evaluation}

Through the rational use of "Superstar" learning software, students can actively participate in the process of formative evaluation of learning effects. While peer evaluation is carried out, students can be encouraged to reflect on their own learning behaviors, which indirectly leads to inspire the learning mechanism of peer promotion.

For example, through the "Grading" activity in "Superstar Platform", teachers will show the evaluation criteria to the students in advance, and the students will grade the speakers according to their own understanding and judgment anonymously. The scores can not only directly reflect the understanding of the respondents on the question, but also indirectly reflect the graders' understanding on the same question.

\section{CONCLUSION}

The Hybrid English Teaching Mode could improve the teaching effect and learning effect. The key to reformation of higher education is to improve students' autonomous learning ability. In view of this, based on the notion that "interest" will promote students' inner motivation for learning, teachers introduce the topics which students are interested, trigger students to think about the questions from the simple to the difficult. By delivering short videos which should be no longer than 10 minutes for each, it could also be the key to promote the fragmented learning. In this way, the teaching efficiency of the whole course could be improved and the learning effect of the students could be strengthened as well.

This course organically combines the first class (traditional classroom activities), the second class (online course) and the third class (extracurricular practice), in order to ensure that students could have a comprehensive grasp of English knowledge 
and application ability. What's more, it could maximize the interaction between teachers and students and could make the students change from "passive learning" to "active learning". Last but not least, this course could achieve the real "learner-centered" objectives during the whole process of teaching.

\section{ACKNOWLEDGMENTS}

Our thanks to ACM SIGCHI for allowing us to modify templates they had developed. The authors gratefully acknowledge the following supports: 1) General Project of Social Science Program of Beijing Municipal Commission of Education "Research on the Communicative Function of Urban Cultural Publicity Discourse in Beijing" (Z19056). 2) Research Project of Education Science of Beijing University of Civil Engineering and Architecture "Research on the Path to Enhance College Students' Cultural Self-confidence from the Perspective of Discourse Analysis of Urban Cultural Publicity in Beijing" (Y19-30). 3) Graduate Education and Teaching Quality Improvement Project in Beijing University of Civil Engineering and Architecture in 2019(J2019006) . 4) Major Project of Beijing Social Science Foundation "Research on the construction of Beijing Urban signs" (Z19121).

\section{REFERENCES}

[1] Zhuo, J. and Cai, C. 2015. Future Teachers in the Trend of Mixed Education: Reflections on Teachers' Diversion, Transition and Teacher Education in the Age of MOOCS, Higher Education Exploration, 04(August 2015), 105-110. (In Chinese)

[2] Graham, C. R. 2013. Emerging practice and research in blended learning. In M.G. Moore (Ed.), Handbook of distance education.333-350. N.Y. : Routledge.

[3] Picciano, A. G., 2016. How meta-analysis can inform online and blended learning research. In C. D., Dziuban, C.D., A.G. Picciano, C.R. Graham et P.D. Moskal (Eds). Conducting research online and blended learning environments: new pedagogical frontiers.43-55. N.Y., USA: Routledge.
[4] Rahardjanto, A., Husamah and Fauzi, A. 2019. Hybrid-PjBL: Learning outcomes, creative thinking skills, and learning motivation of preservice teacher. International Journal of Instruction. 12 (Mar. 2019), 179-192.

[5] Dou, W. N. 2019. Teaching Reform of General Education in Universities Under the Notion of Cross-cultural Ability Cultivation, Educational and Teaching Forum. 13(July 2019), 77-79.DOI= http://www.sciencepublishinggroup.com/journal/paperinfo?j ournalid=501\&doi=10.11648/j.ij11.20190701.11

[6] Zhang, M. 2018. Application of Genre Analysis in Selfevaluation Discourse of English Sci-tech Periodicals Website. Chinese Journal of Scientific and Technical Periodicals. 12(Dec. 2018), 1240-1246. (in Chinese)

[7] Wei, R. 2013. "Cultivation of Critical Thinking in English Reading," Teaching and Management. 27(Sep. 2013), 110112. (in Chinese)

[8] Minkov, M. 2017. A revision of Hofstede's model of national culture: old evidence and new data from 56 countries. Cross Cultural \& Strategic Management. 25 (July 2017), 77-79. DOI= https://www.emeraldinsight.com/doi/abs/10.1108/CCSM-032017-0033

[9] Yan, J. L. 2007. Interpreting the Impact of Foreign Cultures on Chinese Lifestyle by Applying S. Hall' s Model. Journal of Shanghai Normal University. (June 2007), 91-96.

[10] Pely, D. and Shimoni, D. 2019. The Culture of Interest: A Proposed Addition and Revision of the Three - Culture Model. Negotiation Journal. (Feb. 2019), 247-268. DOI= https://onlinelibrary.wiley.com/doi/abs/10.1111/nejo.12287 